\title{
Constructing Spray Pyrolysis System For The Preparation of Thin Films and Study The Optical Properties of PbO Films
}

\author{
Nahida B. Hasan, Mohammed Ahmed Mohammed \\ Department of Physics, College of Science, University of Babylon \\ E-mail address: Iraq_moh_iraq@yahoo.com
}

Keywords: Spray pyrolysis, Lead oxide, Thin film.

\begin{abstract}
In this paper, the design of spray pyrolysis system to prepare thin films of various materials system. The study showed that films prepared with good characteristics. films were prepared from lead oxide $\mathrm{PbO}$ this way. The study of the optical properties of these films and through recording the absorbance spectrum and transmittance spectrum of films prepared in the wavelength range (300-1100) $\mathrm{nm}$. Optical constant for thin films prepared such as absorption coefficient, the extinction coefficient, the refractive index and the optical energy gap was calculated as well. films prepared found that it has a direct energy gap value $3.1 \mathrm{eV}$.
\end{abstract}

\section{INTRODUCTION}

Among different chemical methods, spray pyrolysis technical is most popular today because its application to produce a variety of conducting and semiconducting materials [1]. The fundamental principle involved in the spray pyrolysis technical is the thermal decomposition of the compound to be deposited salts. Spray pyrolysis technique has a list of advantages. Spray pyrolysis technical is a simple and low cost to set up semiconductor thin films. Has the capacity to produce wide area, high quality films attached to standardized thickness [2].Transparent conducting oxide (TCO) thin films such as $\mathrm{PbO}, \mathrm{ZnO}, \mathrm{SnO}_{2}, \mathrm{In}_{2} \mathrm{O}_{3}$ and $\mathrm{MoO}_{3}$ have been studied in detail by many researchers $[3,4]$. These $\mathrm{TCO}_{\mathrm{s}}$ find extensive applications in thin film transistors, solar cells, phototransistors, optical storage devices, gas sensors, photo-thermal and photovoltaic conversions [5-8]. $\mathrm{PbO}$ exists in tetragonal ( $\alpha$-phase) and orthorhombic ( $\beta$-phase) structures at low and high temperatures respectively [9]. The difficulty of preparing exclusively single phase $\alpha$-or $\beta$-PbO was pointed out earlier. The $\alpha$-PbO was obtained earlier by pulsed laser ablation and spray pyrolysis [10]. The $\alpha-\mathrm{PbO}$ was transformed to the meta-stable $\beta-\mathrm{PbO}$ when heat treated beyond $489{ }^{\circ} \mathrm{C}$ [11].

\section{EXPERIMENTAL DETAILS}

\subsection{First: spray pyrolysis system}

A simple homemade spray pyrolysis experimental setup was employed to prepare thin films, The system consists of several parts have been arranged so as to make use of them in the preparation of various the films on various substrates. Figure (1) shows the system in all its parts, and the system consists of the following devices: 


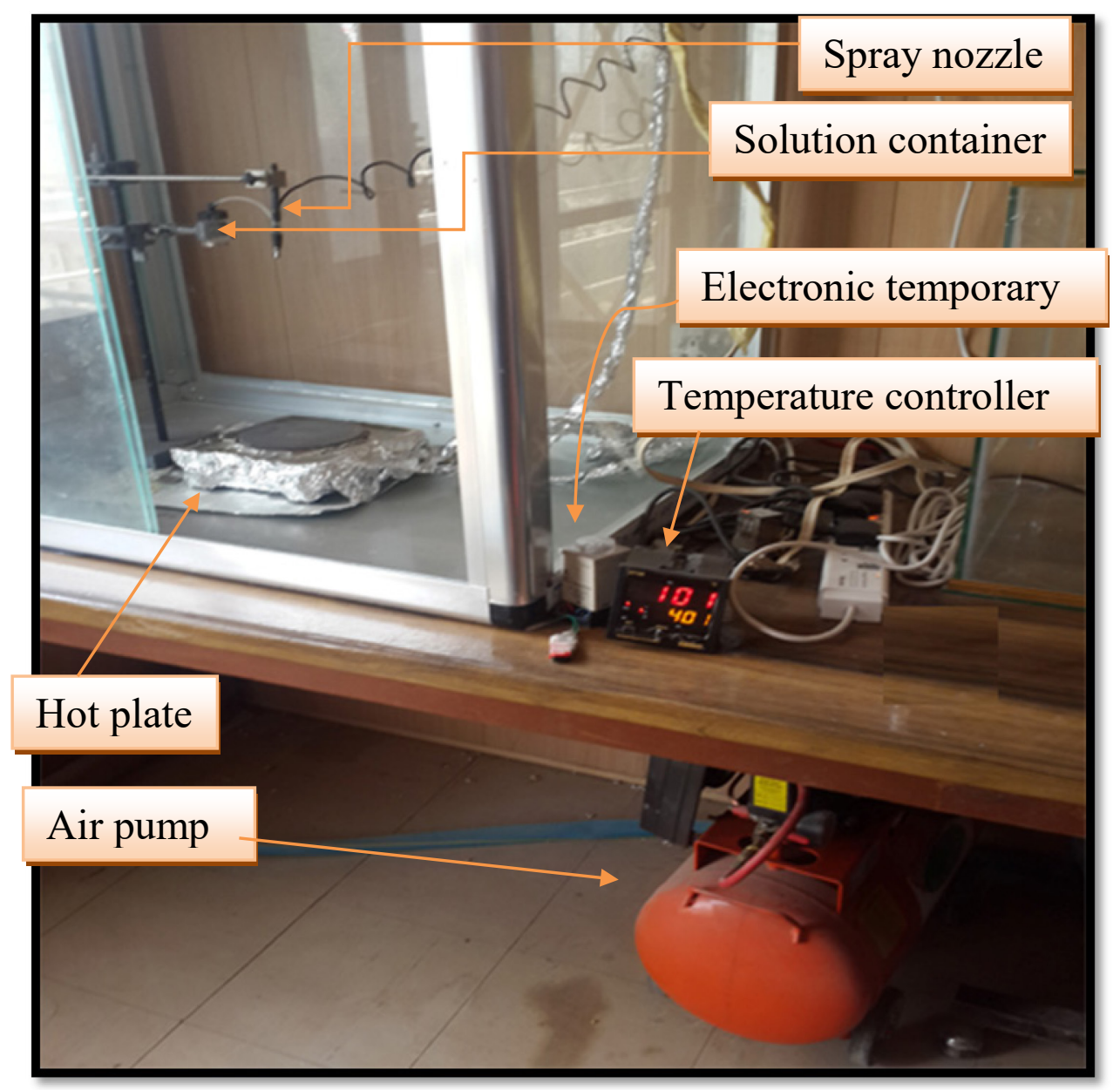

Fig. (1): Chemical Spray Pyrolysis System.

\subsubsection{Spray nozzle}

It is made up of plastic with of an iron head diameter $0.1 \mathrm{~mm}$ contains within it on a piece of iron and other passes through the air and related tube two pieces, one for the transfer of compressed air and the second relates to a small receptacle containing solution from the material to be deposited. As shown in Figure (2).

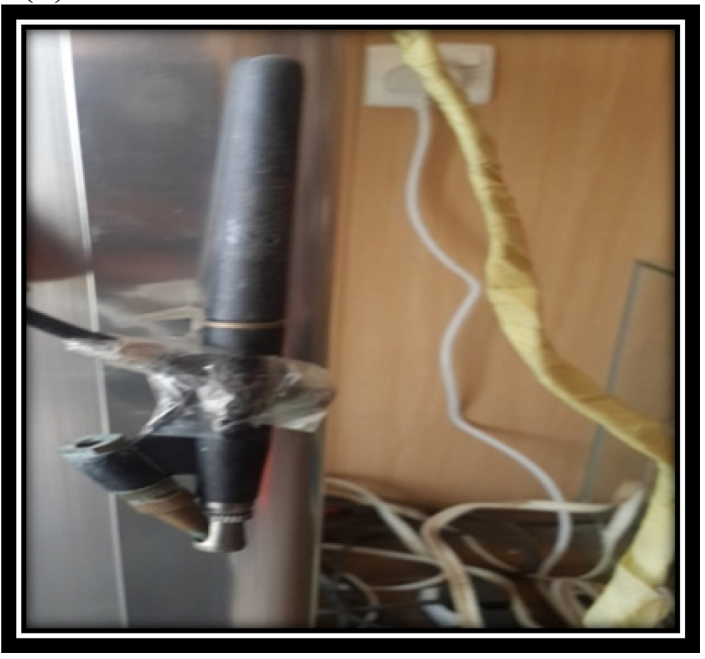

Fig.(2): Spray nozzle

\subsubsection{Hot plate}

The iron disc (with diameter $16 \mathrm{~cm}$ and thickness $0.7 \mathrm{~cm}$ to which $2000 \mathrm{~W}$ heating coil is fixed) served as a hot plate. A maximum temperature of $700 \pm 20{ }^{\circ} \mathrm{C}$ can be achieved with this arrangement. The chromel-alumel thermocouple is used to measure the temperature of the substrates and is fixed at the centre of the front side of the iron plate. The temperature of the hot plate is monitored with the help of temperature controller, as showing in Figure (3). 


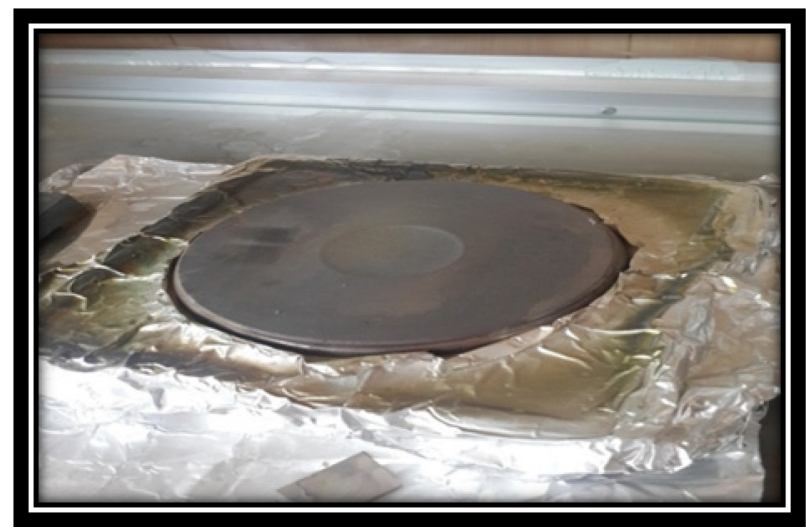

Fig.(3): Hot plate

\subsubsection{Air pump}

It has been used pneumatic pump compressed air to drive inside the tube connected to the spraying. The air pressure is stable here. The compressed air is the useful pushing particulate material deposited is that we want to spray toward the substrate. The air pump show in Figure (4).

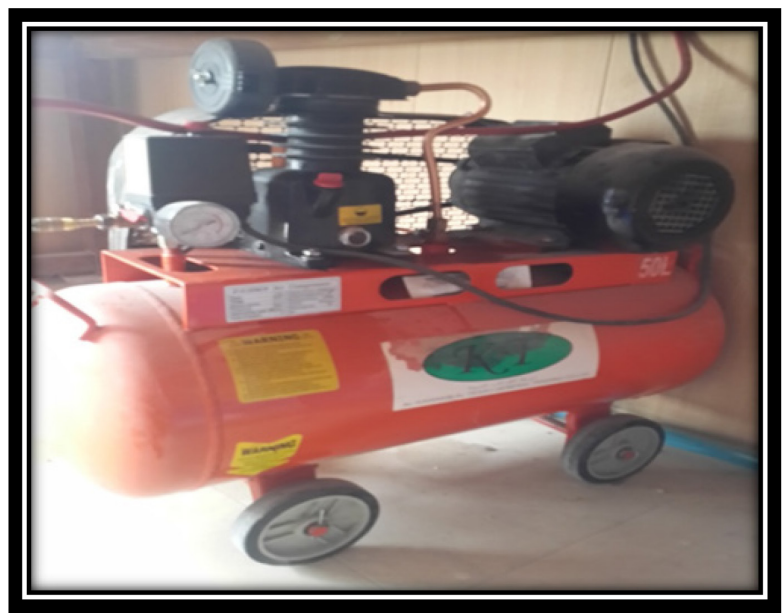

Fig.(4) :Air pump

\subsubsection{Electronic Temporary}

Through its control the number of sprinkles and the time of spraying through a pump or stop pump the air. Where we need to pause after each spray solution on the hot substrate to regain substrate temperature. Because after all spraying the substrate will collide. The electronic temporary show in Figure (5).

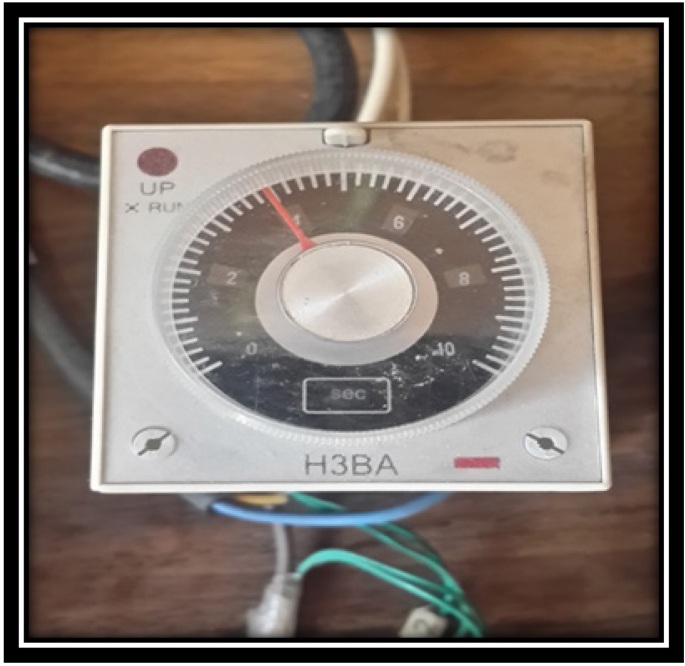

Fig.(5) :Electronic Temporary 


\subsection{Second: Prepared Thin Films}

\subsubsection{Solution Preparation (PbO)}

The $\mathrm{PbO}$ films were prepared by using an aqueous solution of Lead Acetate Dihydrate $\mathrm{Pb}\left(\mathrm{CH}_{3} \mathrm{COO}\right)_{2} .3 \mathrm{H}_{2} \mathrm{O}$ with concentration $0.1 \mathrm{M}$ dissolved in $100 \mathrm{ml}$ of distilled water. The mixture was stirred by(Magnetic stirrer)at $40{ }^{\circ} \mathrm{C}$ for $25 \mathrm{~min}$ and then it was allowed to cool to the room temperature with continuous stirring .

$\mathrm{Pb}\left(\mathrm{CH}_{3} \mathrm{COO}\right)_{2} \cdot 3 \mathrm{H}_{2} \mathrm{O}$ is a powder material which has a white color and its molecular weight (379.33 gm/mol). For calculating mass of $\mathrm{Pb}\left(\mathrm{CH}_{3} \mathrm{COO}\right)_{2} \cdot 3 \mathrm{H}_{2} \mathrm{O}$ in the current experiment the following equation was used:

$$
\mathrm{M}=\frac{W_{t}}{M_{w t .} \times \frac{V}{1000}}
$$

Where:

$\mathrm{M}$ : concentration of molarities.

Wt: weight of $\mathrm{Pb}\left(\mathrm{CH}_{3} \mathrm{COO}\right)_{2} .3 \mathrm{H}_{2} \mathrm{O}$

$\mathrm{M}_{\mathrm{wt}}$ : molecular weight of $\mathrm{Pb}\left(\mathrm{CH}_{3} \mathrm{COO}\right)_{2} \cdot 3 \mathrm{H}_{2} \mathrm{O}$.

$\mathrm{V}$ : volume of distilled water, $(100 \mathrm{ml})$.

\subsubsection{Preparation (PbO) thin film}

A simple homemade spray pyrolysis experimental setup was employed to prepare $(\mathrm{PbO})$ thin films on glass substrates $\left(35 \times 25 \times 1.35 \mathrm{~mm}^{3}\right)$ at a substrate temperature of $375{ }^{\circ} \mathrm{C}$. The deposition parameters such as spray nozzle-substrate distance $(30 \mathrm{~cm})$, spray time $(5 \mathrm{~s})$ and the spray interval $(1 \mathrm{~min})$ were kept constant. The carrier gas (filtered compressed air) flow rate was maintained at $61 / \mathrm{min}$ at a pressure of $6.5 \times 104 \mathrm{Nm}^{-2}$.

Optical transmittance spectra in the wavelength ranging 300-1100 nm were recorded using UV Visible spectrometer (Shimadzu, UV-1601).

\section{RESULTS AND DISCUSSION}

\subsection{Thickness of the (PbO) films}

It was estimated from the mass of the deposited materials using the gravimetric method. Surface diffusion (on the substrate) of the sprayed chemical species makes it very complicated to form a step (in pyrolytic deposition process) required by a conventional thickness profilometry. The standard density of $\mathrm{PbO}\left(9.35 \mathrm{~g} / \mathrm{cm}^{3}\right)$ [12] was used for calculation. The thickness of the films found $150 \mathrm{~nm}$.

\subsection{Optical properties}

Figure (6) show the absorption spectra of the $\mathrm{PbO}$ thin film, The average absorbance for the wavelength of visible region $(500-850 \mathrm{~nm})$ varies between $14-12 \%$.

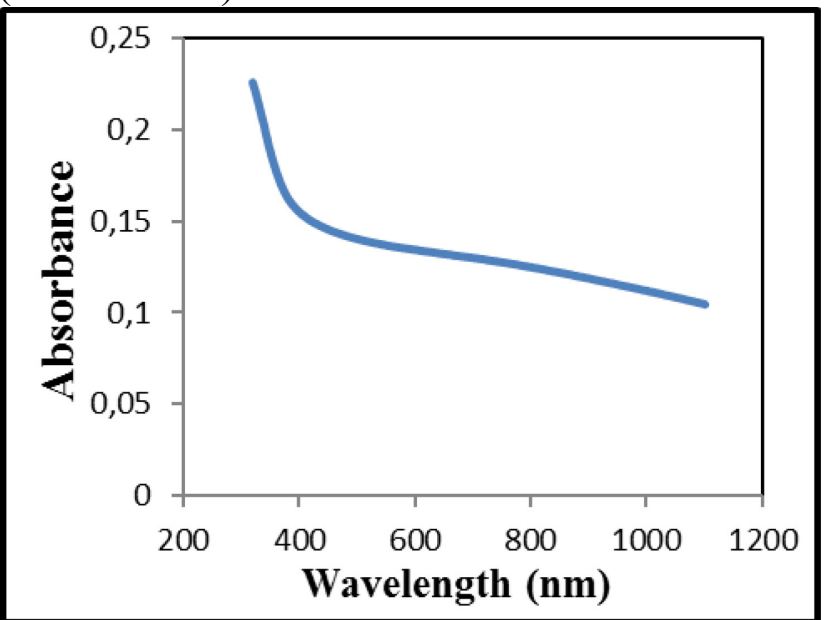

Fig.(6): Absorbance spectrum as a function of wavelength for $\mathrm{PbO}$ film. 
Figure (7) shows the transmittance spectra of the $\mathrm{PbO}$ thin film, The average transmittance in the wavelength of visible region $(500-850 \mathrm{~nm})$ varies between $72-75 \%$.

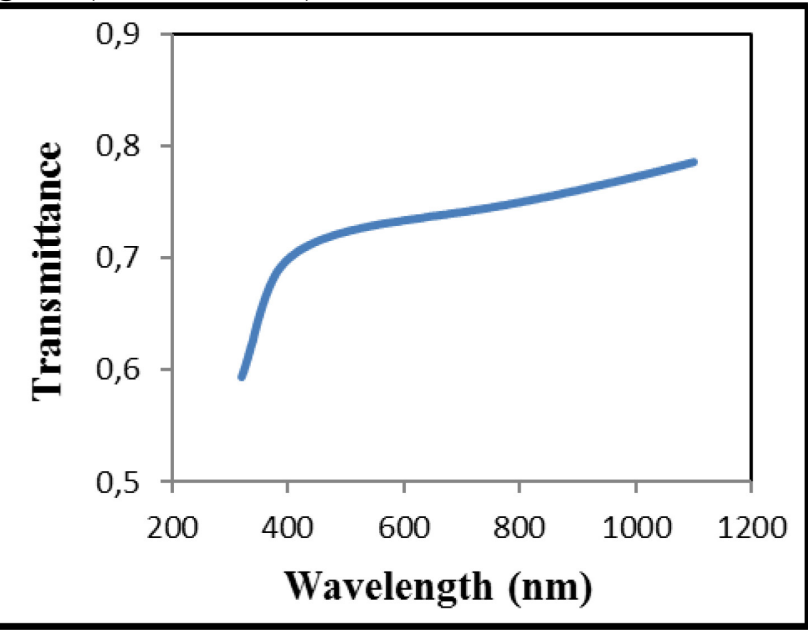

Fig.(7): Transmittance spectrum as a function of wavelength for $\mathrm{PbO}$ film.

Figure (8) shows the absorption coefficient $(\alpha)$ for the prepared thin film which calculated from eq. (2). The values of $\alpha$ for thin film are found to be greater than $10^{4} \mathrm{~cm}^{-1}$ in the visible region, which means that the films have a direct optical energy gap [13], so that the value of $r$ in eq. ( 3 ) is equal to $\frac{1}{2}$.

$$
\alpha=2.303 \frac{A}{t}
$$

Where :

A : absorption.

$\mathrm{t}$ : thickness of thin film.

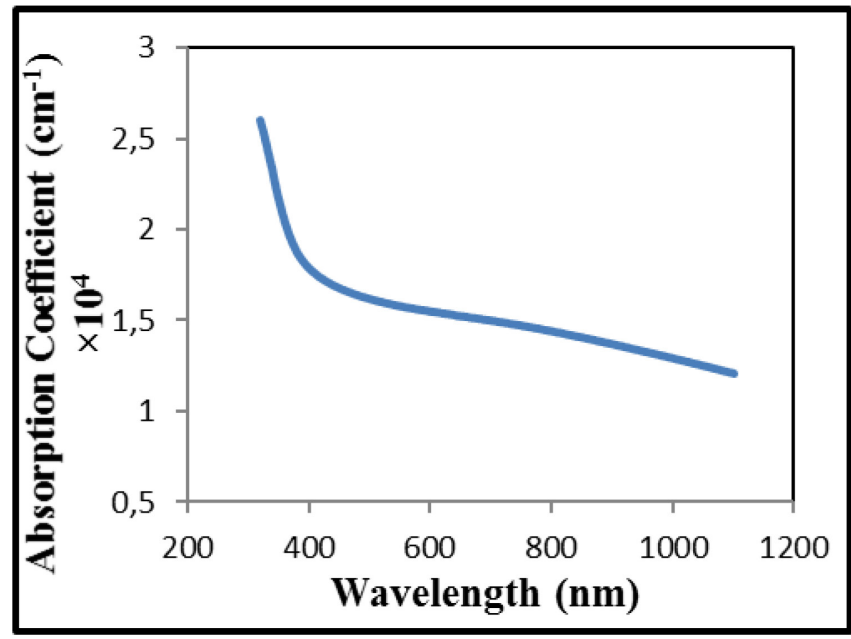

Fig.(8): Absorption Coefficients as a function of wavelength for $\mathrm{PbO}$ film.

The direct optical energy gap ( Eg) was calculated by using the relation ( 3 ) with $r=1 / 2$, and from the Figure (9), the values of $\mathrm{Eg}$ were determined from the intersection point of the extrapolation of a linear curve with hv axis . The energy gap equal $3.1 \mathrm{eV}$.

Where:

$$
\alpha h v=B(h v-E g)^{r}
$$

Eg. : energy gap between direct transition.

B: constant depended on type of material. transition.

$r$ : exponential constant, its value depended on type of transition, $r=1 / 2$ for the allowed direct

ho : photon energy. 
The values of extinction coefficient $(\mathrm{K})$ are calculated using the relation (4). The $\mathrm{K}$ value is plotted vs. $\lambda$.

$$
\mathrm{K}=\alpha \lambda / 4 \pi
$$

Where $\lambda$ : is the wavelength of incident photon rays.

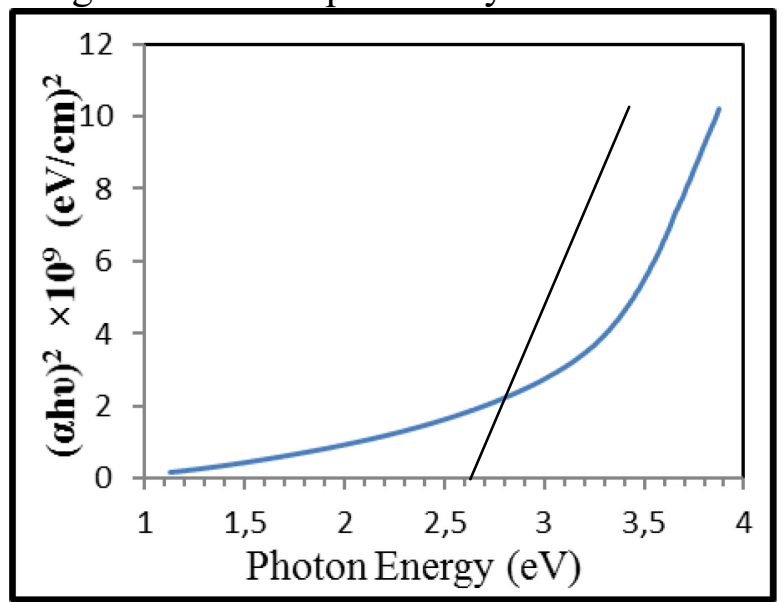

Fig.(9) $(\alpha h v)^{2}$ as a function of ho for PbO film.

The minimum value of $\mathrm{K}$ equal to $56 \times 10^{-3}$ at wave length $400 \mathrm{~nm}$ and increase with increasing $\lambda$ to $105 \times 10^{-3}$ at $\lambda=1100 \mathrm{~nm}$ as show in Figure (10). This means that there are different absorption mechanisms, depending on the film structure.

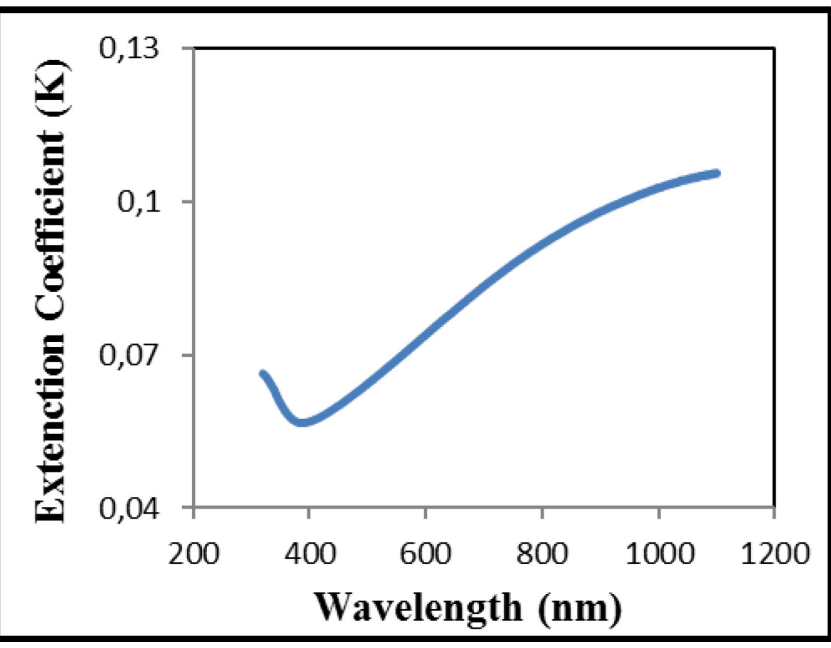

Fig.(10): Extinction coefficient as a function of wavelength for $\mathrm{PbO}$ film.

The refractive index is the ratio between the speed of light in vacuum to it's speed in material which doesn't absorb this light. So the value of $n$ begins when $K$ is constant [1]. The refractive index $(n)$ was calculated from relation (5). The values of $n$ vs. $\lambda$ were shown in Figure (11). 


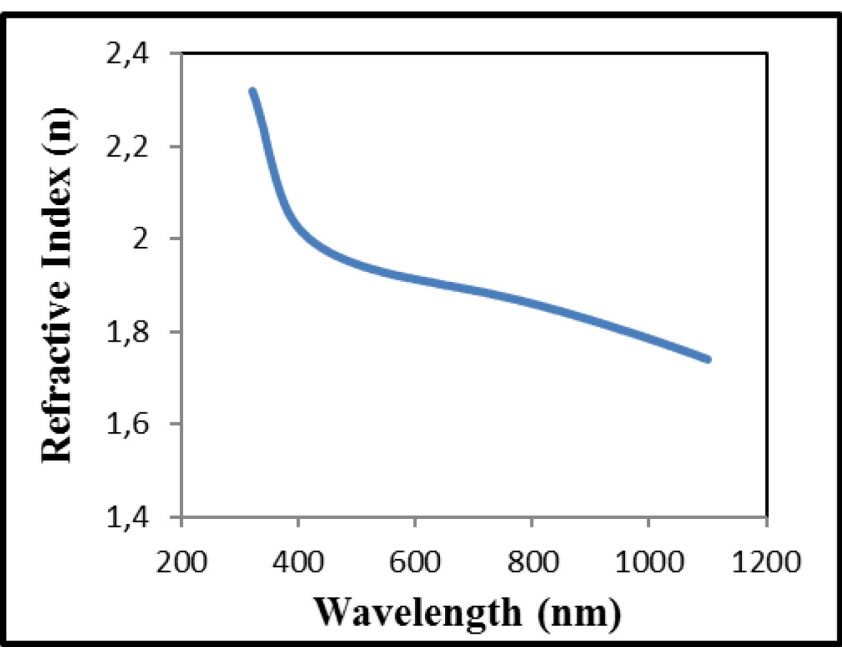

Fig.(10): Refractive index as a function of wavelength for $\mathrm{PbO}$ film.

From the graph $\mathrm{n}$ value decreasing with increasing $\lambda$, the explanation of this behavior may be related to the polarization of thin film because $n$ depends on material polarization where with increasing polarization the velocity of light was decreased so $\mathrm{n}$ changed . The polarization depends on crystalline and on grain size of thin film so these depend on preparation conditions.

$$
n=\left[\left(\frac{1+\mathrm{R}}{1-\mathrm{R}}\right)^{2}-\left(K^{2}+1\right)\right]^{1 / 2}+\frac{1+R}{1-R}
$$

Where :

$\mathrm{R}$ : The reflectance can be calculated from the following equation

$$
\mathrm{R}+\mathrm{T}+\mathrm{A}=1
$$

\section{CONCLUSIONS}

Through the results of a fortress by the optical to geared for films $\mathrm{PbO}$ and compatibility with research and studies numerous conclude that the system that was built for the preparation of thin film materials solid technology, chemical spray pyrolysis useful and accredited for the preparation of thin films certified results for the purposes of research, studies and valid for use in multiple applications results.

\section{References}

[1] S. Wu, Y. Shuai, S. Liyi, Z. Yin and F. Jianhui, "Preparation, Characterization and Electrical Properties of Fluorine-Doped Tin Dioxide Nanocrystals", Journal of Colloid and Interface Science Vol. 346, No. 201, pp. 12-16,( 2010).

[2] Tsai and C. Huang, "Surface Treatment and Characterization of Indium-Tin-Oxide Thin Films Modified Using Cyclonic Atmospheric-Pressure Plasma" ,Japanese Journal of Applied Physics, Vol. 52, No. 2013, pp. 1-7, (2010).

[3] J. Cruz,G.Delgado,R. Perez, S. Sandoval, O. Sandoval, C.I. Romero, J.Marin and O. Angel, Thin Solid Films, Vol.493, p.83, (2005).

[4] B. Thangaraju, P. Kaliannan and Semicond, Sci. Technol. ,Vol.15,p. 542, (2000).

[5] Y. Nagasawa, K. Tabata and H. Ohnish, Appl. Surf. Sci. Vol.121/122 ,p.327, (1997).

[6] A.K. Prasad, D.J. Kubinski and P.I. Gouma, Sens. Actuators, B, Chem. ,Vol.93,p.25, (2003). 
[7] E. Fortunato, P. Barquinha, A. Pimental,A.Goncalves, A.Marques, L.Pereira and R. Martins, Thin Solid Films ,Vol.487 ,p.205, (2005).

[8] W.J. Kim, W.H. Koo, S.J. Jo, C.S. Kim, H.K. Baik, J. Lee, S. Im and J. Vac. Sci. Technol., B 23, p.2357, (2005).

[9] M.I. Baleva, L.N. Bozukov and V.D. Tuncheva, J. Phys. Chem. ,Vol.98 ,p.13308, (1994).

[10] F. Kirkbir,D. Katz, R. Lysse and J.D. Mackenzie, J. Mater. Sci. ,Vol.27 ,p.1748, (1992).

[11] G. Trinquier and R. Hoffman, J. Phys. Chem. ,Vol.88 ,p.6696, (1984).

[12] D.R. Lide ,"CRC Handbook of Chemistry and Physics", $8^{\text {th }}$ edition, CRC Press, p. 4-47 and 465, LLC (1999-2000).

[13] N.C.Ailes -Taylor, R.N.Bicknell , D.K.Blanks , T.H. Myens and J.F.Schetzina , J.Vace. Sci and Technol, A3, Vol.76,(1985). 